\title{
Workshop on reviewing nursing procedures in surgical clinic
}

\author{
Juliana Balbinot Reis Girondi, Daniela Couto Carvalho Barra, Keyla Cristiane do Nascimento, Francis Solange Vieira \\ Tourinho , Darla Lusia Ropelato-Fernandez, Lúcia Nazareth Amante \\ Department of Nursing of the UFSC (NFR-UFSC), Brazil
}

Received: August 28, 2016

DOI: $10.5430 /$ jnep.v7n4p132
Accepted: November 25, 2016 Online Published: December 20, 2016

URL: http://dx.doi.org/10.5430/jnep.v7n4p132

\begin{abstract}
Experience report that aimed to share the experience of teachers in organizing and conducting a workshop for review of nursing procedures geared to the patient in surgical condition. Workshop was attended by 35 students and 7 teachers. Six review stations were organized and the students were divided into six groups. The time at each station was timed and academics made rotated among them. The themes of the stations were oxygen therapy and suction of secretions; nasogastric probing; indwelling catheter and relief; withdrawal points and dressings; parenteral nutrition and peripheral venipuncture. With a focus on the patient in surgical condition, the students were encouraged to reflect, discuss and report on previous experiences on the revised nursing procedures, allowing the active participation and updating of knowledge.
\end{abstract}

Key Words: Perioperative nursing, Education nursing, Education higher, Learning, Nursing care

\section{INTRODUCTION}

The undergraduate nursing program was established by the Federal Decree 76,853 in December 17, 1975, with the aim of preparing nurses to be generalists, critical and committed to the health needs of the population, with the responsibility to assist individuals, families and social groups in their entirety, in the various levels of primary, secondary and tertiary attention.

The political-pedagogical project of the program aims at strategies to promote nursing education with technical and political skills. Its constant changes are based upon school autonomy, solidarity among its teachers and incentives for participation of all in this common and collective project, in line with National Curriculum Guidelines. ${ }^{[1]}$ The course consists in a total workload of 4,860 hours distributed into 10 half-yearly phases. The graduate of the program is ex- pected to be a nurse able to contribute to the development of the profession through education, research, participation in nursing institutions and exercise of social citizenship.

In the context of the fifth phase of the undergraduate nursing course "The Care in the Process of Human Living II-Surgical Health Condition" with total workload of 216 hours distributed into 64 hours of theoretical lessons and 152 hours of theoretical-practical lessons. The components of the course discuss the nursing care provided to adult and elderly under surgical, acute and chronic complications of the living process, the systematization of nursing care in actions of health promotion, recovery and rehabilitation; ethical and bioethical issues of caring for surgical patients; and patient safety.

Among the skills to be developed in the course are: the instrumental, cognitive, affective, social and cultural skills in the process of caring for patients during surgical interven-

\footnotetext{
*Correspondence: Francis Solange Vieira Tourinho; Email: francis.tourinho@ufsc.br; Address: Department of Nursing of the UFSC (NFR-UFSC),
} Brazil. 
tions (does it really only mean during = anesthesia) in the hospital setting; implementation of the Systematization of Perioperative Nursing Care (SPNC) according to the code of Nursing ethics, protecting the rights of the patient, the family, colleagues, the teacher and the multi-professional team in surgical situations. In order to achieve these skills, the undergraduate should at least be able to identify, find basis for and make decisions about the nursing care process in the perioperative period emphasizing the events that may affect the life and recognizing the applicability of patient safety in this care process.

In a world of rapid changes that reflect a computerized and globalized society, the teacher needs to use new strategies as teaching tools to stimulate reflexive, constructive and contextualized practices in this learning universe, sharing with students this co-responsibility. Such reflections are anchored in what is defined by the National Curriculum Guidelines for the Undergraduate Program in Nursing (NCG/NUR) which advocate that the undergraduate student is subject of the training process, of the link between teaching, research and extension/assistance. ${ }^{[2]}$

In this context, the education of health professions has been gaining attention in discussions about improved teaching and learning, what stresses the fragility of traditional pedagogy centered on the teacher as the main holder of knowledge. Reformulated and critical pedagogies emerge, then, with the use of active methods of teaching and learning that support the autonomy of the student, arousing curiosity, stimulating individual and collective decisions, arising from the essential activities of social practice and student contexts. ${ }^{[3,4]}$

Active methodologies help with critical and reflective training of healthcare students and are tools that allow the learning to learn, focusing on core adult learning principles, with appreciation of interaction, to encourage learning by making the future professional to find solutions to relevant issues in the context of professional practice, including all new and different practice settings. ${ }^{[4-8]}$

Thus, this report aims to share the experience of teachers in organizing and conducting a workshop to review nursing procedures geared to the surgical patient.

\section{METHOD}

Teachers of this course meet according to a predetermined schedule at the beginning of each semester to review the teaching plan, prepare the schedule of theoretical and theoretical-practical lectures, schedule technical visits, and evaluate the teaching methods and the process of academic evaluation.
In one of these meetings, and based on the discussions about ways to address the difficulties that students have in relation to nursing techniques/procedures, the teachers listed those procedures that should be revised because of the high frequency with which they are performed in surgical environments (surgical clinic and surgical center). Thus, it was decided to address the following procedures: nasogastric probe; venous puncture; dressings (traditional irrigation technique); long-term and intermittent catheterization; parenteral nutrition; oxygen therapy and suction of secretions.

Nursing procedures were distributed among teachers, who were responsible for reviewing and updating the knowledge, seeking new scientific evidence and also selecting the method for teaching and learning to be applied in every station.

The meeting with students took place in August 2014, in the morning period (from 7: 30 A.M. to 11: 50 A.M.). The place chosen to hold the workshop was the Nursing Laboratory (NURSLAB) of the Nursing Department of the Health Sciences Center. The NURSLAB has three large rooms and offers all the necessary materials for the realization of nursing procedures. Six stations were planned and organized in this physical space. Each station had a teacher. All material necessary for the review, update and demonstration of the previously listed nursing procedures was made available to students.

While six teachers organized the station, a seventh teacher had the task to welcome students in a classroom attached to NURSLAB. At the reception, the students were informed about the dynamics of the workshop by addressing: the procedures to be reviewed; the allotted time for each station ( 25 minutes); time of rotation between each station (5 minutes); division into six groups.

After reception and guidance, the teacher led the students to NURSLAB and this teacher was also responsible for timing the duration and driving the rotation of groups between stations. Figure 1 shows the dynamics used to carry out the workshop to review nursing procedures.

Although each teacher had organized a script for interaction with academics, all started activities at the stations with the following questions: What do you know about this Nursing technique/procedure? Which experience(s) do you have in relation to this nursing procedure? How do you relate the necessity of this nursing procedure to the surgical patient?

Based on the responses of students, the teacher responsible for the station conducted a review of the procedure using a dialogic approach during 25 minutes, ensuring throughout all the time the possibility of students exchange knowledge, previous experiences and clarify doubts. 


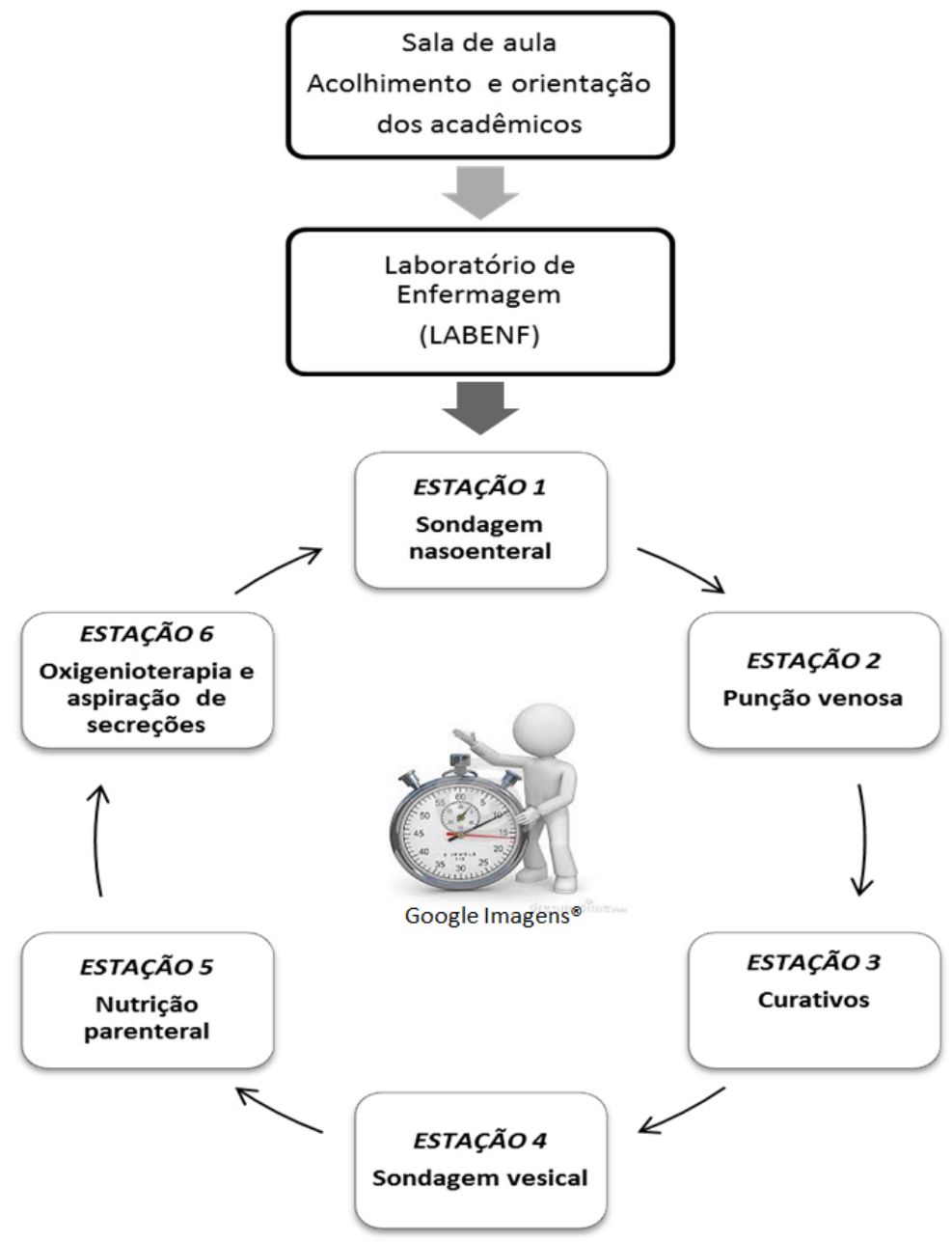

Figure 1. Dynamics of the Workshop to review nursing procedures. Florianópolis, August 2014.

Classroom Reception and provision of guidelines for students: Nursing Laboratory (NURSLAB); STATION 1 Nasogastric probing; STATION 2 Venipuncture; STATION 3 Dressings; STATION 4 Vesical probing; STATION 5 Parenteral nutrition; STATION 6 Oxygen therapy and suction of secretions.

\section{RESUlts}

The workshop was attended by 35 nursing students and 7 teachers. The time was enough to review and clarify doubts. One topic reporting the results of the workshop to review nursing techniques will be presented.

\section{Station 1-Nasogastric probing}

In the context of perioperative nursing care, it is observed that in certain special situations, and depending on the type of surgery the patient has undergone, oral feeding and medication are contraindicated, requiring the implementation of enteral and/or parenteral nutrition.

Nutritional Therapy (NT) "represents the set of therapeutic procedures for maintenance or recovery of the nutritional status of the patient by means of Parenteral Nutrition and Enteral Nutrition". ${ }^{[9]}$ In the Resolution of the Collegiate
Directorate (RCD) $n^{\circ} 63 / 2000$, Enteral Nutrition (EN) is defined as "food for special purposes, with controlled intake of nutrients isolated or combined, with pre-established or estimated composition, specially formulated and developed for oral use or through probes, industrial or not, used solely or partially to replace or supplement oral feeding in malnourished patients or not, according to their nutritional requirements in hospital system, outpatient or home, aiming at the synthesis or maintenance of tissues, organs or systems". ${ }^{[9]}$

From the initial questions above mentioned, other questions were raised in this station, such as: how many students had already performed the procedure and how was this experience with regard to the facilities and difficulties; which are the indications, contraindications, correct positioning of the patient and the probe localization testing. Power Point $R$ 
tools were also used for presenting illustrative figures of the digestive system, the measurement of the probe, patient positioning, X-rays showing the correct placement of the probe, as well as the description of materials used and description of the nursing technique. All materials needed for the procedure were exposed on the station bench, while allowing students to manipulate and simulate the measurement of the nasoenteral probe.

\section{Station 2-Technique of peripheral venipuncture with flexible catheter}

The initial moment with students occurred as described earlier, emphasizing the importance of technical and scientific expertise to the development of this procedure during the perioperative period. It was also highlighted that this technique is directly related to clinical improvement, but that its use can lead to complications such as phlebitis, infiltration, bruising, thrombosis and thrombophlebitis. ${ }^{[10,11]}$

The workshop on the procedure of puncture of peripheral venous access was given through an assessment tool based on the "Fundamentals of Nursing", $[12,13]$ comprising of 24 items. Such items contemplated the steps of nursing technique for venipuncture using a flexible catheter over the needle, as shown in Table 1.

Table 1. Individual assessment tool on the practical ability of peripheral venous access. Florianópolis, August 2014.

\begin{tabular}{|c|c|c|c|c|}
\hline Item & Step & Yes & No & Observations \\
\hline 1 & Wash hands & & & \\
\hline 2 & Make the label and set it in the bottle & & & \\
\hline 3 & Proceed the disinfection of the bottle and connect to the device & & & \\
\hline 4 & Set the date on the device & & & \\
\hline 5 & Remove the air from the device & & & \\
\hline 6 & Connect the extension of two or four ways (polifix) and remove the air from the polifix & & & \\
\hline 7 & $\begin{array}{l}\text { Check if the tray contains: glove for the procedure, transparent dressing or bandage and } \\
\text { tourniquet }\end{array}$ & & & \\
\hline 8 & Guide the patient and explain the procedure & & & \\
\hline 9 & Cut a piece of tape and let it close or open the transparent dressing package & & & \\
\hline 10 & Expose the chosen area & & & \\
\hline 11 & Put on the gloves & & & \\
\hline 12 & Apply the tourniquet at $10-20 \mathrm{~cm}$ from the site to be punctured & & & \\
\hline 13 & $\begin{array}{l}\text { Make local antisepsis with alcoholic chlorhexidine or } 70 \% \text { alcohol, giving time for } \\
\text { action of the product }\end{array}$ & & & \\
\hline 14 & Puncture the vein, observing the bevel up position. & & & \\
\hline 15 & When the blood reflows, pull the mandrel and advance the catheter through the vessel. & & & \\
\hline 16 & Release the tourniquet with the needle partially within the catheter & & & \\
\hline 17 & $\begin{array}{l}\text { Press the site where the catheter is inserted to prevent the backflow of blood and remove } \\
\text { the mandrel }\end{array}$ & & & \\
\hline 18 & Connect the device & & & \\
\hline 19 & Open the serum and observe the drip and the puncture site & & & \\
\hline 20 & Attach the catheter with transparent dressing or bandage & & & \\
\hline 21 & Identify the catheter number, date and name of who punctured. & & & \\
\hline 22 & Adjust the dripping of serum & & & \\
\hline 23 & Collect material and give it appropriate destination & & & \\
\hline 24 & Wash hands & & & \\
\hline
\end{tabular}

Complementary to this instrument, red, white and blue cards were used to guide the activity to be carried out by students: the red card indicated the venipuncture technique; the white card indicated the observation of the technique with the use of Individual assessment tool of practical ability of peripheral venous access and the blue card indicated the discussion regarding the venipuncture technique. Students did not know the meaning of colors. One red card, two white cards and three blue cards were made available by the teacher and students were free to randomly chose cards. We emphasize that all materials needed for the procedure were made available to students.

After observing the student to proceed the venipuncture procedure, the teacher and the other participants of the group 
made the assessment of adequacy of performance (by checking the YES alternative) or inadequate performance (by checking the NO alternative) for each item in the assessment tool.

After completion of the peripheral venipuncture technique by the student assigned for it (red card), the other students recapitulated the steps of this procedure based on the assessment tool. They also clarified subjects they had doubts and explained the main difficulties previously experienced in other scenarios of care.

\section{Station 3-Dressing technique (traditional and irrigation technique)}

After the initial questions, the teacher addressed the review of the procedures of dressing according to the traditional technique and the technique of irrigation; using triggering questions such as: "what are the differences between medical and surgical sterilization?"; "what type of technique was used in making a dressing and which is the rationale"; "how many students had previously performed the procedure and how was the experience regarding the facilities and difficulties met"; "which are the indications and contraindications of each of these techniques?".

In this workshop, opportunity to perform the dressing technique was provided for up to two students from each group, while the other students and the responsible teacher responded questions and/or raised new questions according to the notes and/or the group's expectations. All materials needed for the procedure were exposed on the bench of the station/setting, and students could manipulate them and simulate the technique if they wished.

\section{Station 4-Long-term and intermittent catheterization technique}

After initial questioning, the purpose of long-term and intermittent catheterization during the perioperative period was discussed with students, in addition to the differences presented in the female and male urinary catheter technique. Questions about the caliber of the probe, materials needed for the procedure, patient positioning, among others, were raised by the group.

To resume the knowledge and practical skills of students in the catheterization technique, models with male and female genitourinary system were available, in addition to the materials needed for the procedure. Students had the opportunity to simulate the realization of the catheterization technique in the models under supervision of the teacher, as well as they had the chance to handle materials present on the bench.

\section{Station 5-Parenteral nutrition technique}

During the perioperative period, there are situations in which it is necessary or restore or maintain the nutritional status of the patient. The adequate nutritional status can be achieved by maintaining the gastrointestinal tract at rest or by replacement of proteins taking into account the surgical stress. This supplementation improves nitrogen balance, reduces complications; improves intestinal permeability, activates cellular immunity and produce a better clinical response and decreased length of stay. ${ }^{[14]}$

The Parenteral Nutrition (PN) is defined as controlled supply of nutrients alone or in combination of essential elements for nutrition by deep intravenous ways. However, despite being indicated in special situations, its use can trigger important mechanical, infectious, metabolic and gastrointestinal complications. ${ }^{[15,16]}$

It is important to note that the NP may cause the patient in severe circumstances to develop sepsis because of: use of contaminated materials; multilumen catheters; too much handling of the device; clinical condition of the patient, as well as their underlying diseases; prolonged therapy. Another possible complication is occlusion of the catheter due to mechanical obstruction when there is twisting in the connection of the device; or by blocking the development of clots, stenosis or excessive blood-clotting. Blockage may also be due to the formation of intraluminal crystals by applying incompatible drugs or by the solution of the parenteral nutrition. ${ }^{[16]}$

In this sense, the nursing care is essential for keeping the patient in the best conditions and without risk of infection. For this, the nurse must assess the catheter insertion site in daily basis; maintain the permeability of intermediaries; use the nine certainties at the time of exchange of the bottles, control the temperature of infusion and to be aware of the complaints of the patient regarding pain and discomfort. ${ }^{[14]}$

In view of these considerations, the station was organized over an auxiliary table containing an infusion pump; a serum support, a parenteral nutrition bag; one device of photosensitive serum. After the initial questions, the teacher explained the technique of installation of parenteral nutrition step by step, calling attention to hand hygiene; the nine certainties of administration of medicines; the registration of the infusion in water balance; the source sites of infection for the patient and for the professional. Students were encouraged to participate freely with questions, testimonials, facilities and difficulties faced in performing this technique. At the end of all they assessed as positive and expressed they had resolved many doubts and that they now had acquired new knowledge. Everyone agreed about the nurse's responsibility 
in relation to nursing care to patients in nutritional support with PN.

\section{Station 6-Technique of oxygen therapy and suction of se- cretions}

The main goal of nursing regarding oxygenation during the perioperative period is to maintain ventilation and, thus, avoid hypoxemia and hypercapnia. ${ }^{[17]}$ Thus, careful attention should be given to the use of oxygen and airway clearance.

The station was organized next to the ruler of oxygen and compressed air so that the techniques of oxygen therapy and aspiration of secretion could be presented. A model, materials and equipment were made available for students to carry out these procedures. After the initial questions and the teacher's explanation of the correct handling of suction probes and oxygen catheter, students had the opportunity to simulate the realization of these techniques, as far as they wished so. At the end of rotation between stations, there was a feedback with students, providing opportunities for questions and for reporting the facilities and difficulties while performing these techniques.

\section{Final Considerations}

Critical reflection on the practice is necessary for a significant learning. This must occur through the articulation between the prior knowledge of students with new themes, contextualizing and correlating this knowledge to the new practice, which, at that time, had as scenario the surgical care.
In this perspective, the reflection of teachers points to an enriching process in which the teacher plays the role of advisor and facilitator by providing opportunities for students to learn through a concrete experience, based on their previous experiences and concepts built during other courses of the nursing program.

The experience was based on teaching strategies focused on adult learning, valuing the knowledge of students as protagonists of their learning and integrated with the teachers who are facilitators of this process. Both, teachers and students, are co-responsible for the evolution and for the learning anchored in a transformative and feasible practice in a process of continuous transformation, resilience and new learning.

The continuation of this process as a pedagogical strategy is essential, as they expand the use of active methods of teaching and learning in the referenced issues relevant to the context of professional nursing practice.

It should be noted that the experience of these workshops had a positive impact in the academic life of students during practical activities contributing to the strengthening of skills for nursing care toward surgical patients, as well as the development of communication skills, teamwork and professionalism.

\section{CONFlicts of InTEREST Disclosure}

The authors declare that there is no conflict of interest.

\section{REFERENCES}

[1] Brazil. Ministry of Education National curriculum guidelines of the undergraduate nursing course. Available from: http://portal.m ec.gov.br/cne/arquivos/pdf/Enf .pdf Accessed on November 30, 2015.

[2] Neto DL, Teixeira E, Vale EG, et al. Compliance of the Undergraduate Nursing Courses to the National Curriculum Guidelines. RevBrasEnferm, Brasília. 2007; 60(6): 627-34.

[3] Fernandes JD, Ferreira SL, La Torre MPS, et al. Strategies for the implementation of a new educational proposal in the nursing school of the Federal University of Bahia. RevBrasEnferm. 2003; 56(4): 392-5.

[4] ALMEIDA, Carvalho MT, BATISTA NA. Being a teacher in active methods of teaching and learning in medical training. Rev. bras. educ. med., Rio de Janeiro. 2011; 35(4): 468-476.

[5] Wall ML, Prado ML, Carraro TE. The experience of undergoing a Teaching Internship applying active methodologies. Acta Paul Enferm. 2008; 21(3): 515-9.

[6] Mitre SM, Batista RS, Mendonça JMG, et al. Active teaching and learning methodologies in professional health education: current debates. Science \& Public Health. 2008; 13(Sup2): 2133-2144.

Published by Sciedu Press
[7] Borges TS, Alencar G. Active methodologies in promoting critical training for the student: the use of active methods as a teaching resource in the critical formation of the higher education student. Cairu Magazine. 2014; 03(4): 119-143.

[8] Bollela VR, Senger MH, Tourinho F, et al. Team-based learning: from theory to practice. Medicine (Ribeirão Preto). 2014; 47(3): 293-300.

[9] Brazil. Resolution of the Board of Directors - RCD No 63, of July 6 , 2000. Technical Regulation for Enteral Nutrition Therapy. Available from: http://portal .anvisa.gov.br/wps/wcm/connect/6 1e1d380474597399f 7 bdf 3fbc4c6735/RCD +N\%C2\%B0+63-200 $0 \cdot \mathrm{pdf} ? \mathrm{MOD}=\mathrm{AJPERES}$

[10] Alves LT, Machado PRF, Martins ERC. The academic nursing students and the practice of peripheral venipuncture. RESCAC [online journal]. 2013; 1(1): 232-49. Available from: http://www.rescac .com.br/rescac/index.php/ojs/article/view/19

[11] Oliveira AKA, Vasconcelos QLDAQ, Melo GSM, et al. Instrument of validation for peripheral venous puncture with needled catheter. Rev Rene. 2015 Mar-Apr; 16(2): 176-84.

[12] Padro ML, Gelbcke FL. Fundaments for professional nursing care. 3 ed. Florianopolis: Progressive. 2013. 548p. 
[13] Vaughans BW. Demystified nursing fundamentals: a learning guide. Translation: Rodrigues DC. Porto Alegre: AMGH. 2012. 372p.

[14] Teixeira VB. Indications of glutamine in perioperative parenteral nutrition. (Monograph) Belo Horizonte. 2009. Available from: http://nutritotal.com.br/publicacoes/files/11 65--MonografiaGlutaminaPerioOperatorio.pdf Accessed on April 13, 2015.

[15] Castrao DLL, Freitas MM, Zaban ALRS. Enteral and parenteral nutrition: complications in critically ill patients - a literature review.
Com. Health Sciences. 2009; 20(1): 65-74.

[16] Jesus VC, Secoli SR. Complications on the central venous catheter peripherally inserted (PICC). CiencCuidSaude 2007 Apri/Jun; 6 (2): 252-260. Available from: http://www.periodicos.uem.b r/ojs/index.php/CiencCuidSaude/article/view/4174 Accessed on April 13, 2015.

[17] Passos APP. The nursing care to surgical patients ahead to the anesthesia. Persp. Online: Biology \& Health. Campos dos Goytacazes. 2012; 6(2): 14-19. 